\title{
Critical Care Nurses' Knowledge, Practice, Obstacles and Helpful Measures Towards Palliative Care for Critically III Patients
}

\author{
Afaf Abd El-Aziz Basal ${ }^{1}$, Gehan Abd El-Hakim Younis ${ }^{2, ~ * ~}$ \\ ${ }^{1}$ Medical Surgical Nursing, Faculty of Nursing, Tanta University, Tanta, Egypt \\ ${ }^{2}$ Critical Care Nursing, Faculty of Nursing, Tanta University, Tanta, Egypt \\ Email address: \\ Dr_Gehan_younis@yahoo.com (G. A. El-Hakim Y.) \\ *Corresponding author
}

\section{To cite this article:}

Gehan Abd El-Hakim Younis, Afaf Abd El-Aziz Basal. Critical Care Nurses' Knowledge, Practice, Obstacles and Helpful Measures Towards Palliative Care for Critically Ill Patients. American Journal of Nursing Science. Vol. 6, No. 4, 2017, pp. 293-303. doi: 10.11648/j.ajns.20170604.13

Received: April 8, 2017; Accepted: April 27, 2017; Published: July 5, 2017

\begin{abstract}
Palliative care (PC) is a specialized medical care for people with serious illnesses. It focuses on providing patients with relief from the symptoms, pain and stress of serious illness. The aim of the study is to assess critical care nurses' knowledge, practice, Obstacles and helpful measures toward palliative care for critically ill patients. The research design of this study was a descriptive design. It was conducted at Medical Intensive Care Unit (ICU) at Tanta University Hospital and oncology ICU at oncology institute, Tanta, Egypt. Three tools were used for collecting data. Tool I is a structured interview questionnaire sheet to collect data about nurses' sociodemographic data and knowledge. Tool II is an observational checklist for nurses' practice regarding palliative care and tool III is nurses' perception of obstacles and helpful measures towards palliative care for critically ill patients. The results of the study reported that more than three quarter $(77.1 \%)$ and $(48.6 \%)$ of critical care nurses in medical and oncology ICUs, respectively, had unsatisfactory score of knowledge. More than half (51.4\%) and $25.7 \%$ of nurses in Medical and Oncology ICUs respectively had poor practice while more than one third (34.3\%) and $40 \%$ of nurses in medical and oncology department respectively had good practice score. From this paper, it was concluded that nurses in intensive care units at the Tanta University Hospital had unsatisfactory knowledge and practice regarding palliative care which is considered as an important aspect of improving quality of care. The most obstacles for providing palliative care are "not enough time to provide quality end of life. It was recommended that educational and inservice training programs should be conducted by the nursing personal in both hospital and intensive care settings about palliative care.
\end{abstract}

Keywords: Palliative Care, Intensive Care Nurse, Knowledge, Practice, Obstacles

\section{Introduction}

Critically ill Patients in intensive care units (ICUs) have high symptom burden and experience functional impairments. These patients experience difficulty of communication, pain, dyspnea, and drowsiness [1, 2]. Palliative care (PC) is an important aspect of care for critically ill patients with life threatening illnesses to prevent or relieve physical, psychological, social, emotional and spiritual suffering and improve the quality of life for these patients and their families [3].
PC education increases knowledge of staff, improves nursing skills and enhances their competency [4]. Also, it enhances the quality of care for critically ill patients and assists families in making important decisions about their patient's care. PC can be provided at any time during patient's illness $[5,6]$. Also it is provided by a team of doctors, nurses and other specialists who work together with patients to provide an extra support [7]. Furthermore, PC focuses on symptoms such as pain, shortness of breath, fatigue, constipation, nausea, loss of appetite, difficulty of sleeping and depression. It also helps critically ill patients to gain 
strength for improving their ability to tolerate medical treatments [8].

The care that critically ill patients received at the end of life in ICUs is highly dependent on critical care nurse's knowledge and skills [9]. In addition, the ICU environment is a life-preserving effort, making it difficult for health care providers to shift their treatment goals from curative to palliative or comfort measures. The transition from curative to comfort care requires excellent clinical and communication skills from all caregivers. Because nurses are the caregivers who provide the most direct care and spend most time with patients and their families, it is essential for them to feel empowered and have necessary education and support to provide optimal end-of-life care [10].

Obstacles and barriers to give end of life care in the ICU settings were categorized as health care provider barriers, patients and family-related barriers, and institutional barriers. Health care provider barriers include lack of training for the ICU nurses and poor role models when dealing with death and dying. Many nurses have a lack of experience with death and report that dealing with death is uncomfortable because they fear their own mortality [11]. Poor communication skills are another barrier to provide excellent end-of-life care. Patients and family related barriers include reluctance on the patient and family' part to address end-of-life issues, patient may not be ready to die or is very young. Furthermore, disagreements over goals of care, or language and cultural barriers may contribute to poor end-of-life care [12].

Barriers from an institutional perspective include lack of leadership support for palliative care and a culture that does not support it in the ICU settings. Poor continuity of care, time constraints, and lack of space or privacy to talk about end-of-life issues with patients and their family also, may contribute to poor-quality end-of-life care. In addition, having no protocol for treating the dying patient's symptoms, lack of communication and challenging in a particular group of patients, such as elderly patients, patients in acute care settings, and terminally ill patients are additional barriers to quality end-of-life care $[13,14]$.

Many aspects of critical care nurses' work environment present obstacles to provide quality end of life care. This obstacles as disagreement and conflicts that occur between nurses and physicians regarding different aspects on end-oflife issues, physicians' disregard of patients' wishes for care, avoidance of patients' families, not providing adequate orders for pain relief and level of aggressiveness of treatments and communication [15].

Critical care nurses are the most valuable PC team members after physicians, who address the physical, functional, social, and spiritual dimensions of care [16]. Therefore, the aim of this paper is to assess nurses' knowledge, practice, obstacles and helpful measures towards palliative care for critically ill patient at medical and oncology intensive care unit.

Significance of the study: Critical care nurses are health care providers that caring for critically ill and dying patients daily and spend most of time with stressful situations. In addition, the process of dying in ICUs is complicated, and research on specific obstacles that impede the delivery of PC and supportive behaviors that help in delivery of care is limited. Moreover, published material of both common obstacles and supportive behaviors as perceived by nurses in palliative care were limited.

Aim of the study: To assess Critical care nurses' knowledge, practice, obstacles and helpful measures toward palliative care for critically ill patients.

Research questions:

Q1. What are the higher knowledge and practice scores as reported by critical care nurses?

Q2. What are the most obstacles to provide PC as perceived by critical care nurses?

Q3. What are the most supportive behaviors that help in providing $\mathrm{PC}$ as perceived by critical care nurses?

\section{Subjects and Method}

\subsection{Research Design}

The research design of this study was a descriptive design.

\subsection{Setting}

The study was conducted at Medical ICU at University Hospital in Tanta and Oncology ICU at Oncology Institute, Tanta, Egypt.

Subjects: A convenient sample of 70 nurses who were working in the selected settings was included as 35 nurses from Medical ICU and 35 nurses from Oncology ICU. The total number of nurses in both units was 75 nurse. Five nurses of Oncology ICU were refused to participate in the study without explaining the cause.

The inclusion criteria were nurses having responsibility concerned with direct patient care, having educational status at least diploma in nursing.

The exclusion criteria: Subjects who refused voluntarily to participate in the study.

The data collected during one month at the end of 2016 .

Data collections: The data was collected using the following tools:

Tool I: A structured interview questionnaire sheet. It was developed by the author after reviewing related reviews [17, 18]. It consisted of two parts:

Part A: Nurses' demographic characteristics that include age, qualification, years of experience.

Part B: Nurses' knowledge questionnaire [19] to assess nurses' knowledge regarding palliative care and its philosophy. It consisted of (23) closed ended questions and (4) open ended questions.

It divided into four domains;

i. Definitions of palliative care (two questions).

ii. Aspects of palliative care (ten closed questions and two open questions).

iii. Nursing care of dying patients (five closed questions and two open questions).

iv. Family role toward dying patient (six questions). 
Scoring system: For true and false questions, each correct answer of was given one score and the wrong answer was given zero score. Each (short answer) question was given 2 scores for correct and complete answer, one score for incomplete answers, and zero score for incorrect answers. The total score of knowledge assessment questionnaire was 31. The total level of knowledge was considered "unsatisfactory" for score less than $60 \%$, "satisfactory" for score $60 \%$ to less than $75 \%$, and "good" for score more than $75 \%$.

Tool II: An observational checklist for nurses' practice regarding palliative care. This tool was developed depending on related review to assess nurses performance related to palliative care as assessment, pharmacological management, non-pharmacological management of pain, GIT symptoms and neurological symptoms [20, 21]. It included 21 steps.

Scoring system: one score was allotted for correct step, and zero score was given to incorrect or not done step.

The total score of practice observational checklist was 21 . The higher score indicated higher level of practice. It was classified as "poor" for total score $<60 \%$, "fair" for total score $60-<75 \%$, and "good" for score $>75 \%$.

Tool III: Nurses' perception of obstacles and supportive measures in providing end of life care to critically ill patients 'questionnaires.

This tool was adapted depending on the study of Beckstrand (2005) and Moawad (2013) [20, 21]. This scale had 44 items; 23 obstacle items (using likert like scale as 0 Not an obstacle, 1 Extremely small, 2 Small obstacle, 3 Medium obstacle, 4 Large obstacle, and 5 Extremely large obstacle) and 21 supportive items (using likert like scale as 0 Not Help, 1 Extremely small help, 2 Small help, 3 Medium help, 4 Large help, 5 Extremely large help).

For this current study; some items of the original questionnaires were deleted due to some of these items is repeated and some are not correlated to our culture.

\section{Methods}

\subsection{Ethical Consideration}

Permission to conduct the study obtained from the dean of the Faculty and administrator of the hospital manager.

Official written permissions to conduct this study were obtained from the head of unit.

Written Consent was obtained from each participant. At that time, the researchers offer adequate information about purpose and significance of the study. Participation is voluntary and participants assured that their responses would be confidential and information that might reveal their identity not recorded.

\subsection{Field of Work}

a. The study tool one and two were developed by the researchers based on literature review and tool three was adapted (some modification was done by the researchers). b. Tools validity: The content validity of the developed knowledge questionnaire and observational checklist tools was done by revision of five panels of experts in medical surgical and critical care nursing department to ensure its validity.

c. The reliability of the each tool was confirmed by using Cronbach' alpha test and it was 0.97 for knowledge questionnaire (Tool I). The reliability of the practice Tool II and Tool III were 0.88 and 0.87 respectively.

d. Pilot study: A pilot study was carried out on 5 nurses to test the developed tools for the clarity, applicability, feasibility \& relevance of the tools used. Necessary modifications were done and the 5 nurses of pilot study were included in the study.

e. Data collection for this study was carried out in a period of four months from the beginning of January to April 2016 after revised from experts' opinions. The current study was carried out on two phases: preparation phase and implementation phase.

f. As regards preparation phase, it was concerned with constructing, preparing and testing of different data collection tools, in addition to managerial arrangement to carry out the study. Once official permissions were obtained, the researchers started the implementation phase. Each Nurse who agreed to participate in the study was interviewed individually for 20-30 minutes to answer any questions about the study and submit Knowledge Assessment Questionnaires (Tool 1) during their working shift to be completed in the presence of the researcher to clarify and answer any questions. The researcher checked each questionnaire items to be sure that no missing data were present. Also, the researcher interviewed individually with each nurse to submit the obstacles and helpful questionnaire. It took about 30 minutes.

g. Observation of each nurse during the practice was done during the morning and afternoon shifts in ICU. The rese 3.3 .

\subsection{Statistical Analysis}

The analysis was performed using statistical software SPSS version 23. For quantitative data: mean and standard deviation were calculated. For qualitative data: A comparison between groups was done by using Chi-square test. For a comparison between means of two variables, the t- test was used. A significance was adopted at $\mathrm{P}<0.05$ for interpretation of results of tests of significance.

\section{Results}

Table 1 shows distribution of the studied sample according to sociodemographic data. It was observed that about two third $(60.0 \%)$ and $(62.9 \%)$ of nurses in Medical and Oncology ICUs less than 30 years respectively. Regarding level of education, it was observed that less than two thirds $(62.9 \%)$ of nurses in Medical ICU had Bachelor degree compared to more than one half $(54.3 \%)$ of nurses in 
Oncology ICU. On the other hand, more than one third $(37.1 \%)$ and $(40.0 \%)$ of nurses in Medical and Oncology ICUs had diploma respectively. concerning years of experience, more than one half (57.1\%) less than two thirds $(62.9 \%)$ of nurses in Medical ICU and Oncology ICU had 5 years and more.

Table 1. Distribution of studied sample according to sociodemographic data.

\begin{tabular}{|c|c|c|c|c|c|}
\hline \multirow{3}{*}{ Characteristics } & \multicolumn{4}{|c|}{ The studied sample $(n=70)$} & \multirow{3}{*}{$\begin{array}{l}\chi^{2} \\
\mathbf{P}\end{array}$} \\
\hline & \multicolumn{2}{|c|}{ Medical ICU $(n=35)$} & \multicolumn{2}{|c|}{ Oncology ICU $(n=35)$} & \\
\hline & $\mathbf{N}$ & $\%$ & $\mathbf{N}$ & $\%$ & \\
\hline Age & & & & & \\
\hline Less than 30 years & 21 & 60.0 & 22 & 62.9 & 0.521 \\
\hline 30 and more & 14 & 40.0 & 13 & 37.1 & 0.470 \\
\hline \multicolumn{6}{|l|}{ Level of education } \\
\hline Diploma & 13 & 37.1 & 14 & 40.0 & 1.362 \\
\hline Bachelor degree & 22 & 62.9 & 19 & 54.3 & \\
\hline Years of experience & & & & & \\
\hline Less than 5 years & 15 & 42.9 & 13 & 37.1 & $\begin{array}{l}0.238 \\
0.626\end{array}$ \\
\hline 5 years and more & 20 & 57.1 & 22 & 62.9 & 0.626 \\
\hline
\end{tabular}

Table 2 shows comparison between mean score of knowledge domains of palliative care among critical care nurses. In this table, it was showed that the mean score of definition of palliative care was $(2.77 \pm 1.957)$ among nurses of Oncology Unit where it was $(1.60 \pm 1.752)$ among nurses of Medical ICU with significant statistical difference, where $\mathrm{P}=0.010$. Also, the mean scores of aspects of palliative care, nursing care of dying patients, and family role toward dying patient domains were
(1.14 \pm 1.287$), \quad(7.03 \pm 5.050), \quad$ and $(3.77 \pm 2.658)$ respectively among nurses of Oncology Unit. Significant statistical differences were observed regarding nursing care of dying patients and family role toward dying patient with $\mathrm{P}=0.006$ and 0.035 respectively. Also, total mean score of knowledge was increased among nurses of Oncology Unit (14.71 10.217$)$ than the mean score of medical one $(8.51 \pm 9.316)$ with significant statistical difference where $\mathrm{P}=0.010$.

Table 2. Comparison between mean scores of knowledge domains of palliative care among critical care nurses of Medical and Oncology ICUs.

\begin{tabular}{|c|c|c|c|c|}
\hline \multirow{2}{*}{ Items of domain (1) } & \multicolumn{2}{|l|}{ Mean \pm SD } & \multirow{2}{*}{$\mathbf{t}$} & \multirow{2}{*}{$\mathbf{P}$} \\
\hline & Medical ICU & Oncology ICU & & \\
\hline 1.1 Definition of palliative care & $1.60 \pm 1.752$ & $2.77 \pm 1.957$ & 6.962 & $0.010 *$ \\
\hline 1.3 Nursing care of dying patients & $3.80 \pm 4.536$ & $7.03 \pm 5.050$ & 7.918 & $0.006^{*}$ \\
\hline 1.4 Family role toward dying patient & $2.43 \pm 2.559$ & $3.77 \pm 2.658$ & 4.637 & $0.035^{*}$ \\
\hline Total mean score of knowledge & $8.51 \pm 9.316$ & $14.71 \pm 10.217$ & 7.038 & $0.01 *$ \\
\hline
\end{tabular}

* Significant at level $\mathrm{P}<0.05$

Table 3 shows comparison between mean scores of obstacles of palliative care among critical care nurses of medical and oncology intensive care unit. The mean scores of all obstacles were increased among nurses at oncology unit than at medical one. Also, items of obstacles that received the most extremely and large obstacles among Medical and Oncology Intensive Care Units, respectively were "not enough time to provide quality end-of-life" $(1.37 \pm 1.003)$ and (1.94 \pm 1.187$)$, "poor design of units which do not allow for privacy for dying patients" (1.23 \pm 0.808$)$ and $(1.57 \pm 1.008)$, "dealing with the cultural differences of families" (1.06 \pm 0.684$)$ and (1.74 \pm 0.980$)$, "continuing intensive care for a patient with a poor prognosis" (1.06 \pm 0.684$)$ and (1.43 \pm 0.917$)$, "continuing treatments for a dying patient even though the treatments cause the patient pain or discomfort" $(1.09 \pm 0.702)$ and (1.54 \pm 0.919$)$, "lack of nursing education and training regarding family grieving and quality end-of-life care" $(1.11 \pm 0.718)$ and $(1.83 \pm 0.923)$, "the nurse having to deal with angry family members" (1.74 \pm 1.197$)$ and $(2.11 \pm 1.051)$, "absence of the family for any reason when the patient is dying" $(1.43 \pm 1.290)$ and $(1.57 \pm 1.357)$.

Table 3. Comparison between mean score of obstacles of palliative care among critical care nurses of Medical and Oncology ICUs.

\begin{tabular}{|c|c|c|c|c|}
\hline & \multirow{2}{*}{ Items of obstacles } & \multicolumn{2}{|l|}{ Mean \pm SD } & \multirow{2}{*}{$\begin{array}{l}\mathbf{t} \\
\mathbf{P} \\
\end{array}$} \\
\hline & & Medical ICU & Oncology ICU & \\
\hline 1 & Families not accepting that the physician is telling them about the poor prognosis of the patient. & $0.11 \pm 0.323$ & $1.51 \pm 1.011$ & $\begin{array}{l}60.92 \\
0.00 *\end{array}$ \\
\hline 2 & The nurse deal with distraught family members while still providing care for the patient. & $0.74 \pm 1.010$ & $1.89 \pm 1.157$ & $\begin{array}{l}19.37 \\
0.00^{*}\end{array}$ \\
\hline 3 & Intra-family fighting about whether to continue or stop life support. & $0.54 \pm 0.919$ & $1.37 \pm 1.190$ & $\begin{array}{l}10.63 \\
0.02 *\end{array}$ \\
\hline 4 & The nurse knowing about the poor prognosis of the patient. & $0.17 \pm 0.453$ & $0.97 \pm 1.200$ & $\begin{array}{l}13.61 \\
0.00^{*}\end{array}$ \\
\hline
\end{tabular}




\begin{tabular}{|c|c|c|c|c|}
\hline & \multirow{2}{*}{ Items of obstacles } & \multicolumn{2}{|l|}{ Mean \pm SD } & \multirow{2}{*}{$\mathbf{t}$} \\
\hline & & Medical ICU & Oncology ICU & \\
\hline 5 & Not enough time to provide quality end-of-life. & $1.37 \pm 1.003$ & $1.94 \pm 1.187$ & $\begin{array}{l}4.735 \\
0.03^{*}\end{array}$ \\
\hline 6 & $\begin{array}{l}\text { Poor design of units which do not allow for privacy for dying patients or grieving family } \\
\text { members. }\end{array}$ & $1.23 \pm 0.808$ & $1.57 \pm 1.008$ & $\begin{array}{l}2.465 \\
0.121\end{array}$ \\
\hline 7 & Unit visiting hours those are too restrictive. & $1.03 \pm .169$ & $1.14 \pm .355$ & $\begin{array}{l}2.957 \\
0.090\end{array}$ \\
\hline 8 & The patient having pain that is difficult to control or alleviate. & $1.23 \pm 0.598$ & $1.49 \pm 0.781$ & $\begin{array}{l}2.391 \\
0.127\end{array}$ \\
\hline 9 & $\begin{array}{l}\text { Dealing with the cultural differences that families employ in grieving for their dying family } \\
\text { member. }\end{array}$ & $1.06 \pm 0.684$ & $1.74 \pm 0.980$ & $\begin{array}{l}11.52 \\
0.001 *\end{array}$ \\
\hline 10 & No available support person for the family such as a social worker or religious leader. & $0.86 \pm 0.733$ & $1.00 \pm 0.874$ & $\begin{array}{l}0.548 \\
0.462\end{array}$ \\
\hline 11 & $\begin{array}{l}\text { Continuing intensive care for a patient with a poor prognosis because of the real or imagined } \\
\text { threat of future legal action by the patient's family. }\end{array}$ & $1.06 \pm 0.684$ & $1.43 \pm 0.917$ & $\begin{array}{l}3.693 \\
0.059\end{array}$ \\
\hline 12 & $\begin{array}{l}\text { Pressure to limit family grieving after the patient's death to accommodate a new admits to that } \\
\text { room. }\end{array}$ & $1.11 \pm 0.631$ & $1.71 \pm 0.987$ & $\begin{array}{l}9.176 \\
0.003^{*}\end{array}$ \\
\hline 13 & $\begin{array}{l}\text { Continuing treatments for a dying patient even though the treatments cause the patient pain or } \\
\text { discomfort. }\end{array}$ & $1.09 \pm 0.702$ & $1.54 \pm 0.919$ & $\begin{array}{l}5.474 \\
0.022^{*}\end{array}$ \\
\hline 14 & Family and friends who continually call the nurse wanting an update on the patient's condition. & $1.06 \pm 0.338$ & $1.34 \pm 0.591$ & $\begin{array}{l}6.159 \\
0.016^{*}\end{array}$ \\
\hline 15 & Lack of nursing education and training regarding family grieving and quality end-of-life care. & $1.11 \pm 0.718$ & $1.83 \pm 0.923$ & $\begin{array}{l}13.05 \\
0.001 *\end{array}$ \\
\hline 16 & The unavailability of an ethics board or committee to review difficult patient cases. & $0.86 \pm 0.733$ & $1.66 \pm 1.162$ & $\begin{array}{l}11.87 \\
0.001^{*}\end{array}$ \\
\hline 17 & $\begin{array}{l}\text { Away from the patient and family because of the need to help with a new admit or to help } \\
\text { another nurse care for his/her patients. }\end{array}$ & $0.77 \pm 0.770$ & $1.06 \pm 0.873$ & $\begin{array}{l}2.109 \\
0.151\end{array}$ \\
\hline 18 & Unit or hospital visiting hours those are too liberal. & $0.77 \pm 0.942$ & $1.14 \pm 1.264$ & $\begin{array}{l}1.944 \\
0.168\end{array}$ \\
\hline 19 & Family members not understanding what "life-saving measures" really mean. & $0.06 \pm 0.338$ & $1.80 \pm 1.279$ & $\begin{array}{l}60.76 \\
0.00^{*}\end{array}$ \\
\hline 20 & $\begin{array}{l}\text { The nurse not knowing the patient's wishes for continuing with treatments as the inability to } \\
\text { communicate. }\end{array}$ & $0.97 \pm 0.923$ & $1.26 \pm 1.039$ & $\begin{array}{l}1.480 \\
0.228\end{array}$ \\
\hline 21 & The nurse having to deal with angry family members. & $1.74 \pm 1.197$ & $2.11 \pm 1.051$ & $\begin{array}{l}1.904 \\
0.172\end{array}$ \\
\hline 22 & Absence of the family, for any reason when the patient is dying. & $1.43 \pm 1.290$ & $1.57 \pm 1.357$ & $\begin{array}{l}0.204 \\
0.653\end{array}$ \\
\hline 23 & Family members stay close to a dying person often Interfere with nursing care. & $1.37 \pm 1.262$ & $1.97 \pm 1.150$ & $\begin{array}{l}4.321 \\
0.041 *\end{array}$ \\
\hline
\end{tabular}

* Significant at level $\mathrm{P}<0.05$.

Table 4 represents comparison between mean scores of helpful and supportive measures of palliative care among critical care nurses in medical and oncology departments. This table indicates that the most supportive and extremely large helpful behaviors in providing palliative care to critically ill patients that are perceived by nurses at medical and oncology ICU respectively were "having one family member contact with patient" $(2.60 \pm 1.943)$ and (3.00 \pm 1.847$)$, "having enough time to prepare the family for the expected death" $(2.29 \pm 1.582)$ and $(2.51 \pm 1.401)$, "having the physicians involved in the care of the patient" $(2.40 \pm 1.786)$ and $(2.63 \pm 1.750)$, "the nurse depends on her own previous experience with the critical illness" $(2.46 \pm 1.738)$ and (2.77 \pm 1.497$)$, "having the family help with care of the dying patient" (2.06 \pm 1.327$)$ and (2.43 \pm 1.119$)$, and "having fellow nurses to take care of other patients while you get away from

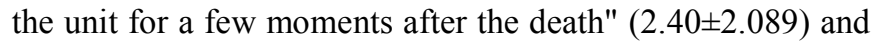
$(3.03 \pm 1.599)$.

Table 4. Comparison between mean scores of helpful and supportive measures of palliative care among critical care nurses in the studied ICUs.

\begin{tabular}{|c|c|c|c|c|}
\hline & \multirow{2}{*}{ Items of helpful and supportive measures } & \multicolumn{2}{|l|}{ Mean \pm SD } & \multirow{2}{*}{$\begin{array}{l}\mathrm{t} \\
\mathrm{P}\end{array}$} \\
\hline & & Medical ICU & Oncology ICU & \\
\hline 1 & Having one family member contact with patient. & $2.60 \pm 1.943$ & $3.00 \pm 1.847$ & $\begin{array}{l}0.779 \\
0.381\end{array}$ \\
\hline 2 & Having enough time to prepare the family for the expected death. & $2.29 \pm 1.582$ & $2.51 \pm 1.401$ & $\begin{array}{l}0.409 \\
0.524\end{array}$ \\
\hline 3 & A unit designed so that the family has a place to go to grieve in private. & $1.69 \pm 1.694$ & $2.03 \pm 1.774$ & $\begin{array}{l}0.684 \\
0.411\end{array}$ \\
\hline 4 & Having the physicians involved in the care of the patient. & $2.40 \pm 1.786$ & $2.63 \pm 1.750$ & $\begin{array}{l}0.292 \\
0.590\end{array}$ \\
\hline 5 & Having a unit schedule that allows for continuity of care of the dying patient by the same nurse. & $1.74 \pm 1.868$ & $3.11 \pm 1.430$ & $\begin{array}{l}11.89 \\
0.001 *\end{array}$ \\
\hline
\end{tabular}




\begin{tabular}{|c|c|c|c|c|}
\hline & \multirow{2}{*}{ Items of helpful and supportive measures } & \multicolumn{2}{|l|}{ Mean \pm SD } & \multirow{2}{*}{$\mathbf{t}$} \\
\hline & & Medical ICU & Oncology ICU & \\
\hline 6 & The nurse depends on her own previous experience with the critical illness. & $2.46 \pm 1.738$ & $2.77 \pm 1.497$ & $\begin{array}{l}0.657 \\
0.420\end{array}$ \\
\hline 7 & Having the family help with care of the dying patient. & $2.06 \pm 1.327$ & $2.43 \pm 1.119$ & $\begin{array}{l}1.602 \\
0.210\end{array}$ \\
\hline 8 & Talking with the patient about his feelings and thoughts about dying. & $1.91 \pm 1.687$ & $2.54 \pm 1.540$ & $\begin{array}{l}2.650 \\
0.108\end{array}$ \\
\hline 9 & Letting the social worker or religious leader take primary care of the grieving family. & $1.80 \pm 1.729$ & $2.80 \pm 1.568$ & $\begin{array}{l}6.425 \\
0.01 *\end{array}$ \\
\hline 10 & Teaching families how to act around the dying patient. & $2.06 \pm 1.909$ & $2.57 \pm 1.577$ & $\begin{array}{l}1.510 \\
0.223\end{array}$ \\
\hline 11 & Allowing families for unlimited access to the dying patient. & $1.17 \pm 1.581$ & $2.03 \pm 1.723$ & $\begin{array}{l}4.702 \\
0.03 *\end{array}$ \\
\hline 12 & Allowing family members to stay alone with the patient enough time after death. & $1.37 \pm 1.239$ & $2.26 \pm 1.094$ & $\begin{array}{l}10.05 \\
0.002^{*}\end{array}$ \\
\hline 13 & Nurses offer words of support to each other. & $2.14 \pm 1.912$ & $2.91 \pm 1.502$ & $\begin{array}{l}3.523 \\
0.065\end{array}$ \\
\hline 14 & Having a fellow nurse to offer support for you after death. & $1.80 \pm 1.587$ & $2.46 \pm 1.421$ & $\begin{array}{l}3.331 \\
0.072\end{array}$ \\
\hline 15 & $\begin{array}{l}\text { Having fellow nurses to take care of other patients while you get away from the unit for a few } \\
\text { moments after the death. }\end{array}$ & $2.40 \pm 2.089$ & $3.03 \pm 1.599$ & $\begin{array}{l}1.998 \\
0.162\end{array}$ \\
\hline 16 & Having a support person outside of the unit to listen to you after the death of your patient. & $1.03 \pm 1.524$ & $2.26 \pm 1.755$ & $\begin{array}{l}9.780 \\
0.003 *\end{array}$ \\
\hline 17 & Having family members thank you or show appreciation for care of their died patients. & $1.57 \pm 2.090$ & $2.57 \pm 1.803$ & $\begin{array}{l}4.592 \\
0.04^{*}\end{array}$ \\
\hline 18 & Having family members accept that the patient is dying. & $1.51 \pm 2.201$ & $2.89 \pm 2.083$ & $\begin{array}{l}7.167 \\
0.01 *\end{array}$ \\
\hline 19 & $\begin{array}{l}\text { Having support staff collect the necessary paper which must be signed by the family before they } \\
\text { leave the unit after death. }\end{array}$ & $1.40 \pm 1.943$ & $2.66 \pm 1.846$ & $\begin{array}{l}7.699 \\
0.01 *\end{array}$ \\
\hline 20 & Physicians giving support in real tangible terms for family. & $1.97 \pm 1.671$ & $2.86 \pm 1.537$ & $\begin{array}{l}5.327 \\
0.02 *\end{array}$ \\
\hline 21 & $\begin{array}{l}\text { The physicians meet with the family after the patient's death to offer support and tell them that } \\
\text { all possible care was done. }\end{array}$ & $2.00 \pm 1.515$ & $2.60 \pm 1.557$ & $\begin{array}{l}2.671 \\
0.107\end{array}$ \\
\hline
\end{tabular}

* Significant at level $\mathrm{P}<0.05$.

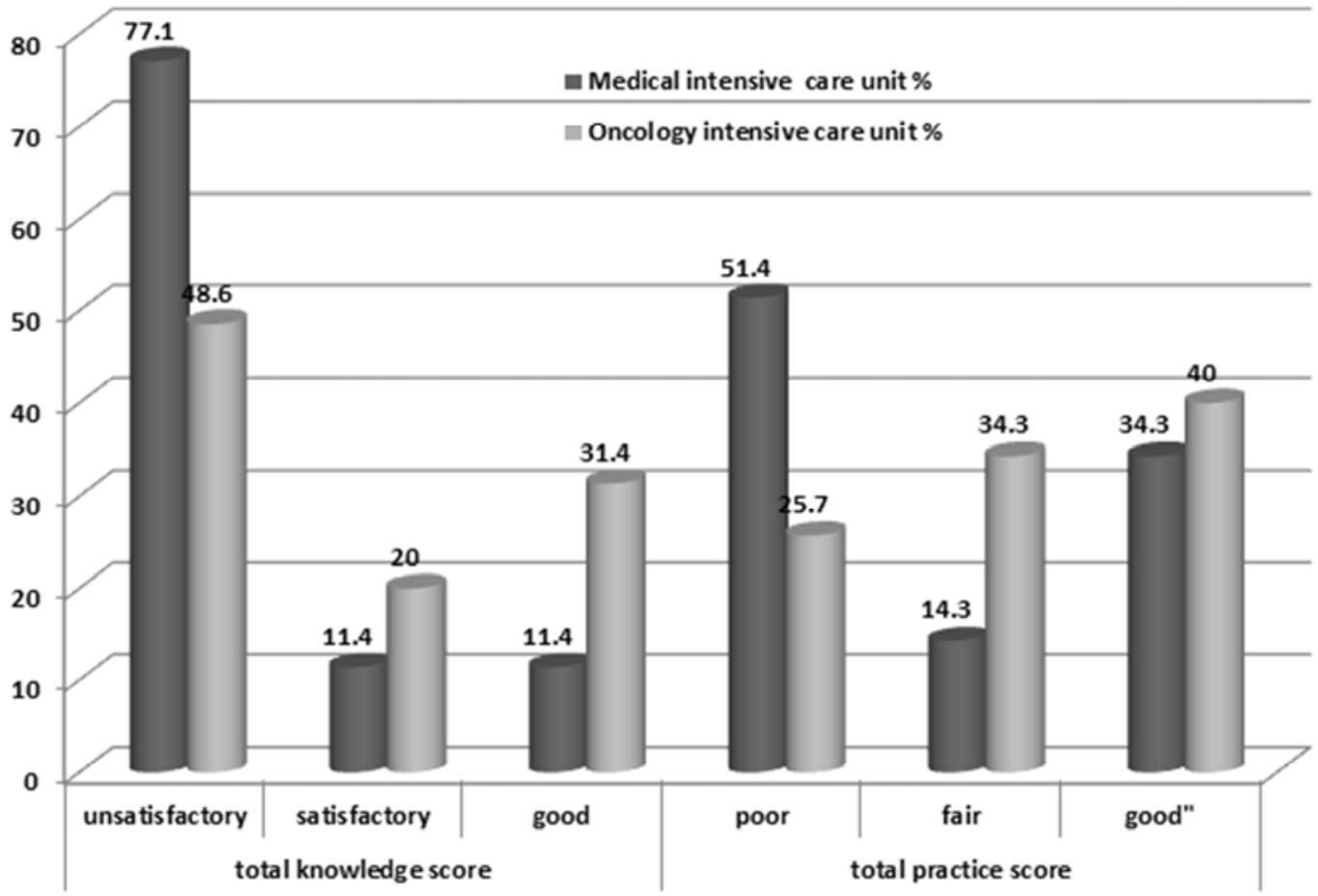

Figure 1. Comparison between total knowledge and total practices score among critical care nurses in medical and oncology ICU.

Figure 1 show comparison between total knowledge and total practices score among critical care nurses at Medical and Oncology ICUs. More than three quarters (77.1\%) and $48.6 \%$ of critical care nurses in medical and oncology 
department respectively had unsatisfactory score of knowledge. There was a statistical significant difference. In relation to total practice score of nurses, more than half of nurses $51.4 \%$ and $25.7 \%$ of nurses in Medical and Oncology Intensive Care Units respectively had poor practice while more than one third (34.3\%) and $40 \%$ of nurses in Medical and Oncology Intensive Care Units respectively had good practice score.

Table 5 represents the effect of age on total practice and total knowledge score among critical care nurses at medical and oncology ICUs. More than half $(54.5 \%)$ of nurses at oncology ICU less than 30 years had good practice score compared with (42.9\%) of nurses at Medical ICU at the same age. On the other hand, half (50\%) of nurses at medical ICU equal or more than 30 years had poor practice score compared with more than one third $(38.5 \%)$ of nurses at oncology ICU at the same level. In relation to total knowledge score, it was observed that the vast majority $(92.9 \%)$ and $(84.6 \%)$ of nurses with age of equal and more than 30 years at medical oncology ICUs respectively had unsatisfactory knowledge score with significant statistical difference with $\mathrm{P}=0.005$. Also, no significant statistical difference was observed among two studied units regarding total practice score.

Table 5. The effect of age on both total practice and knowledge scores among critical care nurses in Medical and Oncology ICU.

\begin{tabular}{|c|c|c|c|c|c|c|c|c|}
\hline \multirow{4}{*}{ Total level } & \multicolumn{8}{|c|}{ Age (in years) } \\
\hline & \multicolumn{4}{|c|}{ Medical ICU } & \multicolumn{4}{|c|}{ Oncology ICU } \\
\hline & \multicolumn{2}{|c|}{$<30$ years $(n=21)$} & \multicolumn{2}{|c|}{$\geq 30$ years $(n=14)$} & \multicolumn{2}{|c|}{$<30$ years $(n=22)$} & \multicolumn{2}{|c|}{$\geq 30$ years $(n=13)$} \\
\hline & $\mathbf{N}$ & $\%$ & $\mathbf{N}$ & $\%$ & $\mathbf{N}$ & $\%$ & $\mathbf{N}$ & $\%$ \\
\hline \multicolumn{9}{|c|}{ Total practice level } \\
\hline Poor & 11 & 52.4 & 7 & 50.0 & 4 & 18.2 & 5 & 38.5 \\
\hline Fair & 1 & 4.8 & 4 & 28.6 & 6 & 27.3 & 6 & 46.2 \\
\hline Good & 9 & 42.9 & 3 & 14.3 & 12 & 54.5 & 2 & 15.4 \\
\hline$\chi^{2}, P$ & \multicolumn{4}{|c|}{$4.468,0.107$} & \multicolumn{4}{|c|}{$5.289,0.071$} \\
\hline \multicolumn{9}{|c|}{ Total Knowledge level } \\
\hline Unsatisfactory & 15 & 71.4 & 13 & 92.9 & 6 & 27.3 & 11 & 84.6 \\
\hline Satisfactory & 2 & 9.5 & 1 & 7.1 & 6 & 27.3 & 1 & 7.7 \\
\hline Good & 4 & 19.0 & 0 & 0.0 & 10 & 45.5 & 1 & 7.7 \\
\hline$\chi^{2}, P$ & \multicolumn{4}{|c|}{$3.204,0.201$} & \multicolumn{4}{|c|}{$10.806,0.005 *$} \\
\hline
\end{tabular}

* Significant at level $\mathrm{P}<0.05$.

Table 6 shows the effect of years of experience on total practice and knowledge scores among studied nurses at medical and oncology ICUs. Nearly two third (60\%) and $45 \%$ of nurses in Medical ICU with experience less than five years and more than five years of experience respectively had poor level of practice. On the other hand, less than two thirds $(61.5 \%)$ and $27.3 \%$ of nurses in oncology ICU with experience less than five year and more than five years of experience, respectively, had good level of practice. In relation to years of nurses' experience and level of knowledge, one fifth (20\%) and less than two thirds $(61.5 \%)$ of nurses in Medical and Oncology ICUs with experience less than five years respectively had good level of knowledge.

Table 6. The effect of years of experience on total practice and knowledge scores among studied nurses at medical and oncology ICUs.

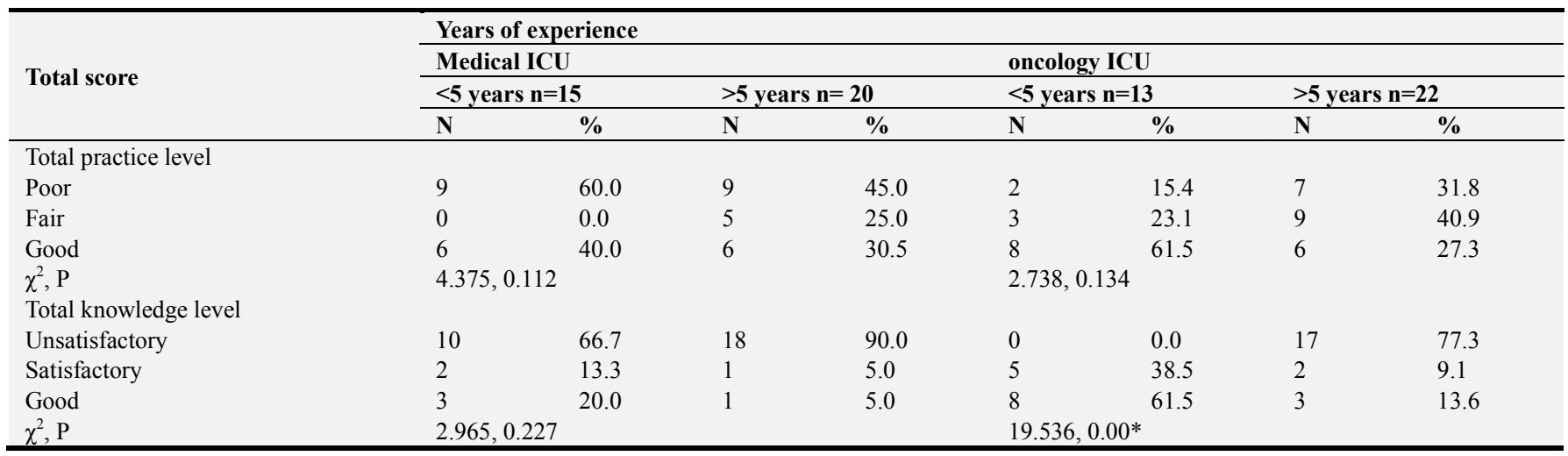

* Significant at level $\mathrm{P}<0.05$.

Table 7 shows the effect of education level on both total practice and knowledge scores among studied nurses at medical and oncology ICUs. In this table, half (50\%) and more than half $(52.6 \%)$ of nurses with bachelor degree in both medical and oncology ICUs, respectively, had poor level of practice. On the hand, less than one fifth (18.2\%) and more than half $(57.9 \%)$ of nurses with bachelor degree in medical and oncology ICUs, respectively had good level of knowledge. 
Table 7. The effect of education level on both total practice and knowledge levels among studied nurses at medical and oncology ICUs.

\begin{tabular}{|c|c|c|c|c|c|c|c|c|c|c|}
\hline \multirow{4}{*}{ Total score } & \multicolumn{10}{|c|}{ Level of education } \\
\hline & \multicolumn{4}{|c|}{ Medical ICU } & \multicolumn{6}{|c|}{ Oncology ICU } \\
\hline & \multicolumn{2}{|c|}{ Diploma $(n=13)$} & \multicolumn{2}{|c|}{ Bachelor $(n=22)$} & \multicolumn{2}{|c|}{ Diploma $(n=15)$} & \multicolumn{2}{|c|}{ Technician Institute (n=1) } & \multicolumn{2}{|c|}{ Bachelor (n=19) } \\
\hline & $\mathbf{N}$ & $\%$ & $\mathbf{N}$ & $\%$ & $\mathbf{N}$ & $\%$ & $\mathbf{N}$ & $\%$ & $\mathbf{N}$ & $\%$ \\
\hline \multicolumn{11}{|l|}{ Total practice level } \\
\hline Poor & 9 & 69.2 & 9 & 40.9 & 6 & 40.0 & 0 & 0.0 & 3 & 15.8 \\
\hline Fair & 3 & 23.1 & 2 & 9.1 & 6 & 40.0 & 0 & 0.0 & 6 & 31.6 \\
\hline Good & 1 & 7.7 & 11 & 50.0 & 3 & 20.0 & 1 & 100.0 & 10 & 52.6 \\
\hline$\chi^{2}, P$ & \multicolumn{4}{|c|}{$6.659,0.036^{*}$} & \multicolumn{6}{|c|}{$5.860,0.210$} \\
\hline Total knowledge level & & & & & & & & & & \\
\hline Unsatisfactory & 13 & 100 & 15 & 68.2 & 15 & 100 & 0 & 0.0 & 2 & 10.5 \\
\hline Satisfactory & 0 & 0.0 & 3 & 13.6 & 0 & 0.0 & 1 & 100.0 & 6 & 31.6 \\
\hline Good & 0 & 0.0 & 4 & 18.2 & 0 & 0.0 & 0 & 0.0 & 11 & 57.9 \\
\hline$\chi^{2}, P$ & \multicolumn{4}{|c|}{$5.170,0.075$} & \multicolumn{6}{|c|}{$31.053,0.00 *$} \\
\hline
\end{tabular}

* Significant at level $\mathrm{P}<0.05$.

\section{Discussion}

Critical care nurses spend more time with dying patients than do other health care practitioners and are responsible for giving care for them. Caring for dying patients and their families is thought to be most stressful to the nurses. Palliative care is to provide spiritual, emotional and physical care [22]. It helps relieve pain and complications associated with illness. Also it enhances the quality of life for critically ill patients and their families and assists them to make important decision about their patients' care $[13,14]$.

Regarding socio-demographic characteristics of the studied nurses, the present study revealed that, about two thirds of critical care nurses in both ICUs aged less than 30 years. Also, most of them had bachelor degree. Also, about two thirds of nurses in both units had years of experience more than 5 years. this result was supported by El-Nagar and Lawend (2013) [23] who stated in a study about" Impact of Palliative Care Education on Nurses' Knowledge, Attitude and Experience regarding Care of Chronically Ill Children "that most of the sample had bachelor degree, also more than one quarter of them had experience ranged from 5-10 years. On the other hand, this result was in contrary with Alshehri and Ismaile (2016) [24] who reported in their study about "nurse's experience of communication with palliative patients" that the majority of nurses had a diploma level in nursing. The level of experience of the target respondents can be described as novice, and work without experience and background.

Regarding the mean scores of knowledge domains related to definition, aspects of palliative care, nursing care of dying patients and family role toward dying patients, the present study showed that the mean scores were decreased in both ICUs. This may be due to absence of in-service training and education programs about palliative care for nurses working at ICUs. Slight and significant improvement among critical care nurses working in oncology unit was observed. This may be due to some nurses were uncomfortable about talking about death with dying patients. the result was supported by Khader et al (2010) [25] who stated in study entitled 'Influence of nurses' characteristics and education on their attitudes towards death and dying" that The quality of nursing care depends on number of factors such as characteristics of nurses, their knowledge, skills and available resources in the unit.

Also, the result was on line with Kassa et al. (2014) [26]. Who stated that the majority of nurses had poor knowledge about palliative care. The possible reason for this might be that only a few nurses have been trained on Palliative care. In addition, Abu-Saad et al. (2007) [27] reported that palliative care needs a holistic approach that emphasizes comprehensive knowledge among health care professionals. Moreover, Iranmanesh et al (2014) [28] illustrated that Palliative care requires nurses to be knowledgeable about different aspects of the care provided for dying patients. Also, Al Qadire (2013) [29] reported that insufficient knowledge of palliative care among nurses is well documented and is considered one of the main obstacles to provide high-quality palliative care services. On the other hand, the study findings are in-consistent with the study findings of Sorifa and Mosphea (2015) [30] about knowledge and practice of staff nurses towards palliative care. They revealed that maximum (79\%) have inadequate knowledge and $21 \%$ have moderately adequate knowledge.

Concerning total practice score, the present study revealed that the level of practice scores about palliative care were unsatisfactory among all nurses. This might be due to lake of in-services training programs for critical care nurses about palliative care. Also, the terminally ill patients haven't special department in the hospitals. So we can find them in all departments. This result was on line with results of Anteneh et al (2016) [31] who stated that more than half $(55.7 \%)$ of respondents had poor practice towards PC.

Regarding the obstacles facing the critical care nurses, the result of the current study showed that the mean scores of all obstacles were increased among nurses at oncology ICU than at medical ICU. Items of obstacles that perceived the most extremely and large obstacles among the two studied ICUs were: "Not enough time to provide quality end-of-life, poor design of units, the patient having pain that is difficult to control, dealing with the cultural differences of families and, continuing intensive care for a patient with a poor prognosis, pressure to limit family grieving after the patient's death to 
accommodate a new admit to that room and, continuing treatments for a dying patient, Family and friends who continually call the nurse wanting an update on the patient's condition and Lack of nursing education and training regarding family grieving and quality end-of-life care and family members stay close to a dying person often Interfere with nursing care consequently. Beckstrand et al (2005) [32] conducted a study about "providing end-of-life care to patients: critical care nurses' perceived obstacles and supportive behaviors" and revealed that the highest scoring obstacles were frequent telephone calls from patients' family members for information, patients' families who did not understand the term lifesaving measures, and physicians disagreeing about the direction of a dying patient's care. Also, the highest scoring supportive behaviors were allowing family members adequate time alone with patients after death, providing peaceful bedside scenes after death, and teaching patients' families how to act around a dying patient. Also Campbell's study (2002) [33] revealed that deficiencies in end-of-life care exist and may be getting worse and more obvious.

Regarding supportive and helpful measures, this result reported that the most supportive and extremely large helpful behaviors in providing PC to critically ill patients that perceived by critical care nurses were "having one family member contact with patient", "having enough time to prepare the family for the expected death", "having the physicians involved in the care of the patient", "The nurse depends on her own previous experience with the critical illness" and "having the family help with care of the dying patient". Also, it was observed that the means scores of all helpful and supportive items were increased among nurses of oncology ICU than that of medical one. This result was in accordance with Pierce (1999) [34] who stated that high perceived supportive behavior score were in the control of nurses. Also, Behaviors controlled by physicians had lower perceived supportive behavior scores because these behaviors are perceived to occur less frequently than do nursecontrolled behaviors.

Regarding the effect of years of experience on total knowledge and practice scores, the current study revealed no significant statistical relationship between years of experience and total knowledge scores; however, there was a relation between years of experience and total practices scores. This may be attributed that nurses with more than 5 years of experience don't update their knowledge and may have no time for searching and increasing their knowledge about PC. Also, some nurses carryout certain aspects of care without knowledge. The current results revealed that nurses working in oncology unit had higher score than working in medical ICU. This result was supported by Morsy et al (2014) [35] who stated revealed that there was no significant statistical relationship between years of experience and total knowledge scores, about one half of the samples in both units with years of experience more than 5 years had good practice score. On the other hand, most of the sample with the same years of experience in both units had unsatisfactory knowledge score. The score of both knowledge and practice for both units were unsatisfactory.

Concerning age, the result showed that no association between age and practice and knowledge scores. This might be due to PC is a novice discipline in Egypt especially in Tanta university. These results were consistent with De Kock F (2011) [36] who reported in a Thesis about "Factors Influencing Nurses' Attitudes towards Caring for Dying Patients in Oncology Settings "that there were negative association of age, gender, work experience, experience of caring terminally ill patients, and duration of training with nurses' knowledge. Also, the result was supported by Grant (2013) [37].

Regarding level of education, the present study showed that nurses who had a higher education degree (BSc.) in this study had increasing knowledge and practices compared to diploma graduate nurses. The reason for this might be bachelorette nurses take the branch of palliative care in their curriculum than that of diploma graduates. This study was supported by Ali et al (2010) [38] who stated in a study about 'Nurses' Attitude towards Caring for Dying Patient in Mansoura University Hospitals" that nurses with a higher education degree (BSc.) had an increasing favorable attitude compared to diploma. Ayed et al (2015) [7] reported that nurses who had a higher education degree had higher mean scores of knowledge compared to diploma graduate nurses.

\section{Conclusion}

Based on the findings of this study, it can be concluded that, nurses in ICUs at the Tanta University Hospital had unsatisfactory knowledge and practice regarding $\mathrm{P} C$ which is considered an important aspect of improving quality of care. Nurses, in this study, are found to have less knowledge than the practice on PC. Most of nurses concluded that the most obstacles for providing palliative care were "Not enough time to provide quality end-of-life, poor design of units, the patient having pain that is difficult to control, dealing with the cultural differences of families and lack of nursing education and training regarding family grieving and quality end-of-life care.

\section{Recommendations}

Based upon findings of the current study, the followings are recommended:

\section{For Nursing Practice}

Educational programs should be conducted by the nursing personnel both in the hospital and intensive care settings on palliative care

For Nursing Education

The importance should be given to palliative care and undergraduate students should be motivated to gain more knowledge and to develop a positive attitude towards palliative care.

For Nursing Administration:

The nurse administrator should plan and organize 
educational programs for nursing personnel on palliative care.

\section{For Nursing Research}

Further study of nurses' attitude, awareness and perception towards care of dying patients in different health care delivery systems.

\section{References}

[1] Aslakson R, Cheng J, Vollen D, Galusca D and Galusca P. Evidence-Based Palliative Care in the Intensive Care Unit: A Systematic Review of Interventions, J Palliat Med. 2014; 17 (2): 219-35.

[2] Puntillo K, Arai S, Cohen N, Gropper M, Nauhaus J, Paul S and Miaskowski C. Symptoms experienced by intensive care unit patients at high risk of dying. Crit Care Med. 2010; 38: 2155-60.

[3] Nelson J, Meier D, Litke A, Natale D, Siegel E, Morrison S. The symptom burden of chronic critical illness. Crit Care Med. 2004; 32: 1527-34.

[4] Nelson J, Puntillo K, Pronovost P, Walker A, McAdam J, Ilaoa $\mathrm{D}$ and Penrod J. In their own words: Patients and families define high-quality palliative care in the intensive care unit. Crit Care Med 2010; 38: 808-18.

[5] Sharon L and Docherty. Searching for the Dying Point Providers Experiences with Palliative Care in Pediatric Acute Care, Ped. Ng. 2007; 33 (4): 335-41.

[6] Patrick A, Palmieri. The Anatomy and Physiology of Error in a Verse Health Care Events Advances in Health Care Management, 2008; 7: 33-68.

[7] Ayed A, Saye j, Harazneh L, FashafshehI and Eqtait F. The Nurses' Knowledge and Attitudes towards the Palliative Care, Journal of Education and Practice. 2015; 6 (4): 91-99.

[8] Connor M. Understanding the Influence of Palliative Nursing: A Global Perspective Int J Palliate Nursing, 2009; 15 (7): 3167.

[9] Reink L, Shannon S and Engelberg R. Nurses Identification of Important Yet Under-Utilized End of Life Care Skills for Patients with Life Limiting or Terminal Illness, J Palliate Med. (2010); 13 (6): 753-59.

[10] Harris M, Gaudet J, O’ Reardon C. Nursing care for patients at end of life in the adult intensive care unit, Journal of Nursing Education and Practice, 2014; 4 (6).

[11] Clarke E, Curtis J, Luce J. Quality indicators for end-of-life care in the intensive care unit, Crit Care Med. 2003; 31 (9): 2255-62.

[12] Granek L, Krzyzanowska M and Tozer R. Oncologists' strategies and barriers to effective communication about the end of life, J Oncol Pract. 2013; 9 (4): 129-34.

[13] Ahmed N, Bestall J and Ahmedzai H. Systematic review of the problems and issue of accessing specialist palliative care by patients, careers and health social care professionals, Palliat Med. 2004; (18): 525-42.

[14] Carlton B. The Barriers to and Evidence for Palliative Care, Journal of Pediatric Hematology/Oncology. (2011); (33): 132-
35.

[15] Bradley E, Cherlin E, McCorkle R, Fried T, Kasl S and Cicchetti D. Nurses' use of palliative care practices in the acute care setting. J Prof Nurs. 2001; 17 (1): 14-22.

[16] Egan KA, Abbott P. Interdisciplinary team training- preparing new employees for the specialty of hospice and palliative care. J Hosp Palliat Nurs, 2002; 4.

[17] Das A and Haseena T. Knowledge and Attitude of Staff Nurses Regarding Palliative Care, International Journal of Science and Research (IJSR), 2015; 4 (11).

[18] Aslakson R, Cheng J and Vollenweider D. Evidence-based palliative care in the intensive care unit: A systematic review of interventions, Journal of palliative medicine, 2014; 17 (2)

[19] Prem V, Karvannan H, Kumar S, Karthikbabu S, and Syed N. Study of Nurses' Knowledge about Palliative Care: A Quantitative Cross-sectional Survey, Indian J Palliat Care. 2012; 18 (2): 122-27.

[20] Beckstrand R and Kirchhoff K. providing end-of-life care to patients: critical care nurses' perceived obstacles and supportive behaviors, American Journal of Critical Care. 2005; 14 (5).

[21] Moawad G A. Nurses' perception of obstacles and supportive behaviors in providing end of life care to critically ill pediatric patients, Journal of Biology, Agriculture and Healthcare, 2013; 3 (2): 95-105.

[22] Liu J, Mok E and Wong T. Caring in nursing: investigating the meaning of caring from the perspective of cancer patients in Beij ing, China. J. Clin. Nursing. 2006; (15): 188-96.

[23] El-Nagar S and Lawend J. Impact of Palliative Care Education on Nurses' Knowledge, Attitude and Experience regarding Care of Chronically Ill Children Journal of Natural Sciences Research. 2013; 3 (11): 94-103.

[24] Alshehri $\mathrm{H}$ and Ismaile $\mathrm{S}$. Nurses' experience of communication with palliative patients: Saudi experience, International Journal of Advanced Nursing Studies. 2016; 5 (2): $102-8$.

[25] Khader K, Jarrah S and Alasad J. Influence of nurses' characteristics and education on their attitudes towards death and dying: A review of Literature, International Journal of Nursing and Midwifery, 2010; 2 (1): 1-9.

[26] Kassa H, Murugan R, Zewdu F, Hailu M, and Woldeyohannes D. Assessment of knowledge, attitude and practice and associated factors towards palliative care among nurses working in selected hospitals, Addis Ababa, Ethiopia, BMC Palliative Care, 2014.

[27] Abu-Saad H and Dimassi H: Pallative care in Lebanon: knowledge, attitude and practice of physician and nurses. J Med Liban, 2007; 55 (3): 121-128.

[28] Iranmanesh S, Razban F, Tirgari B and Zahra G. knowledge about palliative care in Southeast Iran, alliative\& Supportive Car. (2014); 12 (3): 203-10.

[29] Al Qadire M. Knowledge of palliative care: An online survey, Nurse Education Today J Palliat Care Med, 2015; 1-4.

[30] Sorifa B and Mosphea K. Knowledge and Practice of Staff Nurses on Palliative Care, IJHRMLP, 2015; 01 (2): 41-45. 
[31] Anteneh S, Kassa H, Demeke T and Guadu T. Assessment of Nurses' Knowledge, Attitude, Practice and Associated Factors towards Palliative Care: In the Case of Amhara Region Hospitals, Advances in Biological Research, 2016; 10 (2): 110-23.

[32] Beckstrand R, Kirchhoff K. Providing end-of-life care to patients: critical care nurses' perceived obstacles and supportive behaviors, American Journal of Critical Care, 2005; 14 (5): 395-403.

[33] Campbell L. End of life care in the ICU: current practice and future Hopes. Crit Care NursClin North Am, 2002; 14: 197200.

[34] Pierce S. improving end-of-life care: gathering suggestions from family members. Nurs Forum. April-June. 1999; 34: 514
[35] Morsy W, Elfeky H and Mohammed S. Nurses' Knowledge and Practices about Palliative Care among Cancer Patient in a University Hospital - Egypt, Advances in Life Science and Technology. 2014; 24: 100-13 available at www.iiste.org.

[36] De Kock F. Factors Influencing Nurses' Attitudes towards Caring for Dying Patients in Oncology Settings in the Western Cape Metropole. MSc. Degree Thesis, Stellenbosch University, 2011.

[37] Grant L, Downing J, Namukwaya E, Leng M, Murray SA: Palliative care in Africa. BMJ Support Palliative Care, 2011; 1: $118-22$.

[38] Ali W and Ayoub N. Nurses'attitude towards caring for dying patient in Mansoura University Hospitals. J Med Biomed Sci, 2010; 1 (1): 16-23. 